\section{Childhood epilepsy}

Continuous spikes and waves during slow sleep A Beaumanoir, $M$ Bureau, $T$ Deonna, CA Tassinari, eds. pp xi+250, illustrated. John Libbey \& Company Limited, London, 1995. £32.00, hardback.

Participants at a workshop held in Milan in October 1993 describe their experience of continuous spike and wave activity during slow sleep (CSWS). Children affected by this relatively rare syndrome have atypical absence seizures when awake and a variety of seizure types during sleep, with characteristic electroencephalographic abnormalities during sleep. A total of 25 European groups presented papers on the natural history, investigation and treatment of these syndromes. The participants also submitted details of their individual cases: the 155 cases available are individually reported and the group is then analysed in the final chapters.

The better understanding of the epileptic syndromes is crucial to the management of childhood epilepsy. The CSWS syndrome has often been regarded as 'benign' because the seizures are usually self-limiting, a view which is not supported by the case histories analysed. The affected children show marked cognitive impairment during the episodes and many are left with persisting impairment, always affecting the verbal modalities most severely. Indeed children may present with progressive aphasia before seizures are apparent, originally described as Landau-Kleffner syndrome.

This book will be of interest to paediatric neurologists and neurophysiologists who may wish to share in the wider experience of this uncommon condition. It will also be of interest to those interested in the development of speech.

\section{MICHAEL HAYWARD \\ Walton Centre for Neurology and Neurophysiology, Liverpool L9 1AE, UK}

\section{Obesity}

Progress in obesity research: vol 7 , A Angel, $\mathrm{H}$ Anderson, C Bouchard, et al, eds. pp. xvi+768, illustrated. John Libbey, London, 1996. $£ 70.00$, hardback.

This book concerns the edited proceedings of the Seventh International Congress on Obesity held in Toronto in August 1994. This was a landmark conference because of the new scientific information which was presented, especially as regards the genetics of human obesity, human B3 adrenoceptor, transgenic mice and the role of the adipocyte as an endocrine organ. There were many more new developments highlighted at this conference which the editors have included in the 106 chapters which make up this book. The chapters are grouped under six major headings, each chapter concisely written with a summary, introduction, main results and their significance, liberally illustrated and with a reasonable reference list. Such a book is often used solely as a reference guide and therefore the ability to browse easily is essential. This is helped by the short but detailed summaries at the start of each chapter, fully written references and a reasonable index. The range of topics covered is extensive and includes cell biology, energy expenditure, body composition, epidemiology, appetite regulation, eating disorders, visceral fat metabolism, public health issues, and the prevention, management and treatment of obesity. In other words, there is something here for everyone interested in this subject.

Simultaneous presentations at conferences result in delegates missing certain sessions and hence the value of such edited proceedings as a transcription of all sessions; a service not to be underestimated. Nevertheless, such proceedings are most useful when read soon after the event and so it is regrettable that it has taken 18 months for publication. In the meantime the scientific area of obesity has been galvanised by the discovery of the $o b$ gene, its product leptin, the association with neuropeptide $\mathrm{Y}$ and the sympathetic system, the potential role of TNF-alpha, the genetic abnormalities of the B3 adrenoceptor in man and the latest population studies. This rapid advance has meant that this book based on a conference two years ago is dated and potential readers should be aware of this. Other areas of obesity such as management have not advanced at such a frenetic pace and this leaves much which is timely and relevant for the reader.

ROLAND JUNG Ninewells Hospital, Dundee, DD2 IUB, UK

\section{Quality management}

The textbook of total quality in healthcare AF Al-Assaf, JA Schmeme, eds. pp. ix +301 , illustrated. Kogan Page, London, 1995. Hardback.

This book is written as a textbook for students of total quality. There are 11 contributors, all of whom have a different style. One of the editors (AF Al-Assaf) has written a number of chapters, and some chapter introductions. His style is very readable, and he has the ability to make complex concepts (eg, data management) very readable and easy to understand. The chapters in the book cover such areas as the history and principles of total quality, methods of implementation and tools for assessing progress; the costs of quality; and its relationship to the law. Each chapter is well-referenced.

Chapter 3 contains a series of essays which are considered classics in the field. These provide a very good background to the concepts of total quality. Some chapters (eg, that covering the law, ethics and total quality) were written from an American viewpoint, and the detail would not be relevant to readers from other countries. Others (eg, How to start a direct patient care team), though practical, seemed to me to be over-prescriptive in describing the process, down to suggestions for the meeting agenda. There is some duplication between chapters, because each chapter is written to stand alone.
Overall, I would see this book as a useful one to use as additional reading for students of total quality (rather than as a main textbook). For those in the field, it could be a useful reference book.

DIANA FORREST Liverpool Health Authority, Hamilton House, Liverpool, $L 3$ 6AL, UK

\section{Anaesthesia}

Quality and safety in anaesthesia, JS Walker, ed. pp 212, illustrated. BMJ, London, 1994. £16.95, paperback.

Death during anaesthesia is rare; in the order of 1 in 200000 anaesthetics. Morbidity is significant, however; in addition to pain, patients frequently complain of nausea, vomiting, headache or sore throat post-operatively. Indeed, it is the absence of such complaints which, for the patient, differentiates a good anaesthetic from a miserable one. Anaesthetists must therefore constantly strive to improve their anaesthetic technique. This little book discusses how audit can be used to improve such standards. It also details how peri-operative monitoring and safer equipment can improve morbidity and mortality rates.

Eleven authors have contributed; not all are anaesthetists. A consultant in healthcare quality discusses the value of medical audit, by auditing pre-operative assessment. A psychologist discusses safety in aviation; the task of flying an aircraft has often been compared with anaesthesia. In general, anaesthetists are interested in this comparison, (although, in contrast, aircraft pilots do not seem to have the same curiosity about anaesthesia!). This chapter makes entertaining reading; it highlights how any disaster is rarely due to one error alone; it is usually due to a multiplicity of faults. Now that trainees work in shifts, it is pertinent to note that handing over from one anaesthetist to another during an operation has as many advantages as disadvantages. The problem of underarousal may be prevented by a fresh approach, but confusion may occur, causing the relief anaesthetist to act inappropriately. As with any book that considers recent developments in training, for instance, the specialist registrar grade or changes to the fellowship examination, some aspects are already out of date.

One of the most stimulating chapters is the discussion of critical incidents in anaesthesia, which details the history of such reporting and gives an analysis of the advantages and disadvantages of this type of data collection. Anaesthetists may not have given much thought to such limitations previously.

It would be appropriate for every department of anaesthesia to possess this book: it only costs $£ 16.95$. Every anaesthetist would benefit from reading it; it could not fail to concentrate the mind.

JM HUNTER

University Department of Anaesthesia, Royal Liverpool University Hospital, Liverpool L69 3BX, UK 